\title{
AN ANALYSIS ON THE EFFECTS OF CORONAVIRUS (COVID-19) ON THE FINANCIAL MANAGEMENT OF MULTINATIONAL CORPORATIONS
}

\author{
Nurul Mohammad Zayed \\ Assistant Professor \& Head \\ Department of Real Estate \\ Daffodil International University, Dhaka, Bangladesh \\ E-mail: zayed.bba@daffodilvarsity.edu.bd \\ K. M. Anwarul Islam \\ Associate Professor \\ Department of Business Administration \\ The Millennium University, Dhaka, Bangladesh \\ E-mail: ai419bankingdu@gmail.com \\ Shahiduzzaman Khan Shahi \\ Independent Researcher \\ Department of Real Estate \\ Daffodil International University, Dhaka, Bangladesh \\ E-mail: shahi27-334@diu.edu.bd \\ Md. Sazidur Rahman \\ Executive Officer \\ Dutch-Bangla Bank Limited, Dhaka, Bangladesh \\ E-mail: sazid191017@gmail.com \\ Tahsin Sharmila Raisa \\ Lecturer \\ Department of Business Administration \\ Daffodil International University, Dhaka, Bangladesh \\ E-mail: raisa.bba@diu.edu.bd
}

\begin{abstract}
This paper develops a sensible framework to get a handle on the spatiotemporal plans of the COVID-19 event, its real nature, and its implications to the Financial Management of MNCs (Multinational Corporations). In the most straightforward structure, the construction of multinational Corporations is included a parent organization that holds all licensed innovation rights, contract makers or undeniable makers which complete the creative work in the nations with low work costs, and the restricted or undeniable wholesalers that sell the completed merchandise in different business sectors and behaviors market explores in their nations of activity. The pandemic effect on financial movement contrasts as far as extent and force. This
\end{abstract}


has delivered unrivaled proportions of shortcomings. This paper tries to diagram the overall elements of worldwide Financial Management of MNCs (Multinational Corporations) with country explicit dangers and primary dangers. Fundamental data is accumulated from different online media, adroit journals, various kinds of examination papers, and other online sources, etc. The globalization of Financial Management of MNCs (Multinational Corporations) is coordinated to the enormous extension of greatness and enhancement of monetary exchanges. At long last, all areas show and portray in detail this subject and give a few suggestions to conquer the present circumstance.

Keywords: Coronavirus, COVID-19, International, Financial Management, Multinational Corporations, Economy, Market.

\section{JEL Classification Codes: F36, G32, F23.}

\section{INTRODUCTION}

The COVID-19 episode has just started to influence how financial specialists carry on across economies, i.e., starting from the way of life and socialization to monetary exercises of individuals and firms. The financial effects of the new coronavirus ("COVID-19"), which arose in Wuhan, China in December 2019 and spread to the world in a brief time frame with the commitment of between reliance among nations, happen at an exceptional level contrasting with emergencies experienced previously.

The International Financial Market is where budgetary wealth is traded among individuals (and between countries). It will, by and large, be viewed as a wide blueprint of rules and establishments where resources are exchanged between specialists in overabundance and managers in insufficiency and where affiliations set out the standards. Also, found on this market is a wide scope of widespread trade. Along these lines, this market is a pointer to the moneyrelated turn of events. As of now daily of COVID affects the everyday issue.

A Multinational Corporation (MNC) is an organization that works in its nation of origin, just as in different nations around the planet. It keeps a focal office situated in one country, which arranges the administration of all its different workplaces, like regulatory branches or manufacturing plants. In the easiest structure, the construction of worldwide undertakings is contained a parent organization that holds all protected innovation rights, contract makers or undeniable makers which do the creative work in the nations with low work costs, and the restricted or undeniable wholesalers that sell the completed merchandise in different business sectors and behaviors market explores in their nations of activity (contingent upon the conditions).

The financial effects of the COVID-19 happen at an exceptional level contrasting with the emergencies experienced previously. For some businesses, both the store network has been hindered and client request has contracted simultaneously. Restructurings and changes in transfer pricing policies will be inescapable for the progression of organizations and exercises since the COVID-19 emergency has caused an unanticipated worldwide danger acknowledgment that couldn't be anticipated when the intra-bunch legally binding connections were set up and the gathering activity model was planned. Albeit the presence of conditions that require the requirement for strategy changes is frequently viewed as negative, it can likewise be transformed into a chance by worldwide endeavors. 
Additionally, this reciprocal pressing factor contrasts from one industry to another, yet besides from one country to another and even from one area to another inside a similar country. Removed the common wellbeing impacts of local or worldwide arising and endemic irresistible disease, occurrences spread more extensive financial results that win frequently not mulled over in harm's way or impact examinations. The far-reaching arrangement among financial specialists about the transnational money-related shut down because of the sickness pandemic is perceived to be the significant determinant of securities exchange instability that could supervise the biggest financial exchange impact in the 21 st century.

During the COVID-19 scourge, the whole world is going through on an edge of affliction. As a result of this infection was massively destructive. Every country has just embraced a technique to confine the stretch. A few nations have endured safety measures through open separation techniques, like shutting off scholarly associations, confining work, and limiting the portability of individuals. These arraignments have had a fast and significant impact on all economies around the world. The disintegration sought after because of reduced creation, the allowances in particular administrations that need close human association, the joblessness of workers because of this scourge, deterring numerous organizations incidentally and endlessly brought about a tremendous impact on the worldwide economy.

The pandemics COVID-19 period has annihilated the production network in the worldwide economy. This is going on with both the nearby and worldwide business sectors. Worldwide market harmony is a distant memory. The essential utilization of organic market harmony is imbued into everyday activities whether somebody is a rancher, drug producer, scholarly, or a buyer. Market interest is critical for the economy since they influence the expenses of buyer items and ventures inside an economy. As per the hypothesis of the market economy, the association among market interests adjusts a point, which is known as the harmony cost or market balance. Market balance is something vital for the global economy. How a market works with the standard market interest measure, it consequently will in general accomplish the harmony in a point. Due to the worldwide pandemic, supply is tremendously diminished where request generally stays as before.

The prudent exchange of everywhere in the world is influenced generally. Coronavirus impact has now expanded past reasoning ability. This epic pandemic caused the biggest misfortune in financial history. The worldwide financial exchange has fallen. There is a deficiency of merchandise, staple goods, medications, machines, and gadget pieces of clothing items, food sources, oil, and so on in creation or an inventory organization, the individuals who are working if one individual gets influenced can without much of a stretch influence other.

From a business perspective, there is a connection between each country on the planet so the assets produced in one nation are provided to another nation dependent on interest. The creation of merchandise has normally declined because of the conclusion of plants, individuals' pay has gone down because of the conclusion of the working area, because of which the interest for the item has additionally diminished and the stockpile has halted. So unique organization halted their creation only hence and supply moreover. They need to think often about their specialist's wellbeing. Worldwide security is likewise a major issue there.

This contamination affected worker's lost compensation and all buyers cut back on spending and in like manner, the stockpile shock has incited a lot greater interest to paralyze. This paper recreates the impacts of (COVID-19) on the interest and supply of the global economy and how the decreasing popularity for administrations occurred and the decrease in the inventory of items that occurred due to joblessness and different aftermaths. 
It is anyway too quick to even think about expecting the outcome of COVID-19 on the Financial Management of MNCs (Multinational Corporations). The world depends on a full measurable sign. It is hard to assess the results and the aftermaths of the pestilence as it circles and to explicitly ascertain what amount of time it will require countries to withdraw to normal monetary movement.

\section{LITERATURE REVIEW}

The COVID-19 comes in to see close to the completion of December 2019 in China (Chahrour, 2020). The COVID-19 spread rapidly in Wuhan. The specialists in Wuhan made extreme walks and lock the city on January 23, 2020 (Xiang, 2020). Inside a large portion of a-month, instances of COVID-19 were distinguished in a few distinct countries and soon it transformed into an around the world fear (Spina, 2020). The World Health Organization (WHO) broadcasted the crown plague a pandemic (WHO, 2020a). As of March 29, the disease had spread to more than 177 countries and debased 722,435 patients, achieving 33,997 passings (Johns Hopkins University, 2020). Watching critical flare-ups out-breaks in China, Europe, Iran, South Korea, and the United States began to make starting strides (Khachfe, 2020). WHO communicated that Europe had become the new point of convergence of the pandemic on March 13 (WHO, 2020b). China took powerful action and winning concerning diminishing new cases. Deplorably, this diminishing was not the circumstance in various bits of the world, including Iran, Italy, the US, and other European countries (Remuzzi, 2020). To give a reaction to COVID-19, unique nations have now presented travel limitations (both inside and outside) to forestall the stretch of the infection. General wellbeing organizations and government experts are taking assessments like social disconnecting, self-separation, or withdrawal (Bedford, 2020). Jim (2020) decided "Associations encountering reduced benefits, more important working costs or pay difficulties because of COVID-19". It has been conveyed that as the world is encountering the slump monetarily to revamp and recuperate the economy will be over the long haul because of the extraordinary enormous negative result of the COVID-19 to the world economy. Ruiz Estrada (2020) investigated the chance and hugeness of a plague are appended to the financial elements of a comparable district. It is conceivable to expect that the result of Wuhan COVID can cause a broad financial disturbance. Ye (2020) found that gauges that worked in the rearward in a sad economy don't work today if the radix of the matter isn't tended to. The capital market today is very different from years prior when financial backers expect the fundamental organization grade before making a variety to their portfolio. Today in this existence where calculations are testing to discover how much the market can spill or rise. Buheji (2020) examined the savagery of these contaminations transport individuals vacillates from light to perilous. Mann (2020) said Manufacturing will show a ' $\mathrm{V}$ ' or ' $U$ ' shape and administrations, will experience an 'L' shape. Amassing excess from assembling plant end represents a likely danger in the near term, by and by, creation will power to restock inventories once confines end and creation lines resuscitate. During the term of organizations, the race to the movement business, transportation organizations, and the family unit works out, generally, won't be recovered, and the indisputable set back of overall advancement will also trouble the L-formed vent of interest for these nontrade able organizations. Furman (2020) expressed the impact of COVID-19 is another stun for the economy, which has never shown up before. Gopinath (2020) called attention to that the financial effect of this infection is expanding altogether harshly and as of now obvious in numerous nations. China is the case of that sort of economy where from the initial two months in 2020 creation and assembling area exercises were strongly declined. Mauro (2020) cautioned 
that the pandemic could effectively affect agricultural nations. Ramelli (2020) demanded, "These early outcomes propose that the market decently fast started to react to worries about the conceivable financial results of the novel COVID". Baret et al. (2020) guaranteed that the COVID-19 has huge outcomes on the normal financial business areas. This COVID-19 has impacted the inventory and impacts the overall economy. There are constraints on making an excursion from one country to the next. During voyaging, amounts of cases are perceived as positive, especially taking worldwide visits. All legislatures, wellbeing affiliations, and various experts are perseveringly glancing in on perceiving the cases impacted by the COVID. Clinical benefits specialists face various inconveniences in staying aware of the idea of clinical benefits (Chinazzi, 2020). Hoque et al. (2020) depicted that the reinforcing of the Coronavirus is being thought to cause a drawn-out impact on the movement business of the country China by using assistant data. Antonakakis et al. (2013) saw time-fluctuating associations among monetary trade returns, engaging precariousness and approach weakness. Their revelations suggested that the connections are doubtlessly time-fluctuating and oil demand dazes and the US decline captivating. McKibbin et al. (2020) showed that an included erupt can essentially influence the overall economy in the short run. Chang et al. (2020) demanded that COVID-19 has adjusted the world endlessness and has drastically the worldwide travel, the travel industry, and accommodation organizations, which are profoundly powerless to pivotal stuns like COVID-19. It is vital to investigate how these indispensable businesses will recover and proceed with feasibility in a cutting-edge world pronouncement after COVID-19. Baret (2020a) battled that the COVID-19 has significant outcomes on the regular monetary business sectors as recently the world saw the breakdown of offers, oil, capital, and bonds all through the world. On account of the assorted macroeconomic stuns, bank borrowers' people and firms face a high danger of default (Vidovic, 2020). Notwithstanding default hazard, banks may likewise confront a liquidity emergency as numerous contributors may decide to pull out their investment funds to help their living and wellbeing costs (Baret, 2020b). In the pandemic, pay openings for individuals and partnerships become progressively restricted, which may constrain them to gobble up their investment funds. Especially, individuals losing positions will frantically attempt to get by on their reserve funds. This, whenever preceded for long, will cause a liquidity deficiency and cutoff the loaning limit of banks (Cheney et al., 2020). The financial area may see a shoot-up in default danger and rates due to diminished earnings and money inflows to their borrowers because of the monetary stoppage and constrained closure. The emergency will be more awful for borrowers depending on fares to the worldwide market, as the world economy battles to endure the pandemic. These impacts will be extreme additionally for private companies whose solitary help is doing everyday business and creating sufficient working money inflows to endure (Dua et al., 2020). Because of financial stoppage locally and worldwide, interest for credits will droop and it has just been going on in numerous economies. As firms limit their activity and creation, interest for both short-and long-haul financing decays considerably, which has no chance of bounce back until the monetary itself recuperate (Ryan et al., 2020)? Barua (2020) studied that the pandemic could influence global connections by influencing the current and the forthcoming financial projects under the public authority to government (G2G) collaboration especially among China and different economies. Because of the flare-ups, China-upheld public undertakings under-speculation or help structures have come to stop as materials and venture staff can't go to and for bringing about postponements or abrogation of G2G help or venture programs as China and their accomplice nations. 


\section{OBJECTIVES}

The significant goal of this paper is to find the effect of the COVID-19 on the Financial Management of MNCs (Multinational Corporations). The specific targets are to locate the current point of view on the world economy for the explanation of COVID-19, COVID-19 repercussions for the world budgetary market, and the world market breakdown little by little and colossal moves in the stock organization. Recognizing the components and factors, which are identified with the Demand and Supply of the International Economy to the pandemic circumstance? Discover the gathering and situational impacts that influence the Financial Management of MNCs (Multinational Corporations). Deciding the various factors, which influence the Financial Management of MNCs (Multinational Corporations).

\section{METHODOLOGY}

The methodology of this study is mainly qualitative. The authors adopted a systematic literature review from recent distributions. The wellsprings of data are gathered from various types of writing, recent articles, reports which depend on the predominant pandemic circumstance. This structure is put together eventual outcomes of COVID concerning the Financial Management of MNCs (Multinational Corporations). For this evaluation, in any case, the optional data was endeavored circumspectly before managing them.

\section{RESULTS \& DISCUSSIONS}

UNIDO's information showed a steady decrease in underway development, demonstrating a by and large financial lull as of now before the episode of the COVID-19 emergency. Assembling yield development fell underneath the milestone of 1 percent and stayed at 0.7 percent in the final quarter of 2019 (Figure 01).

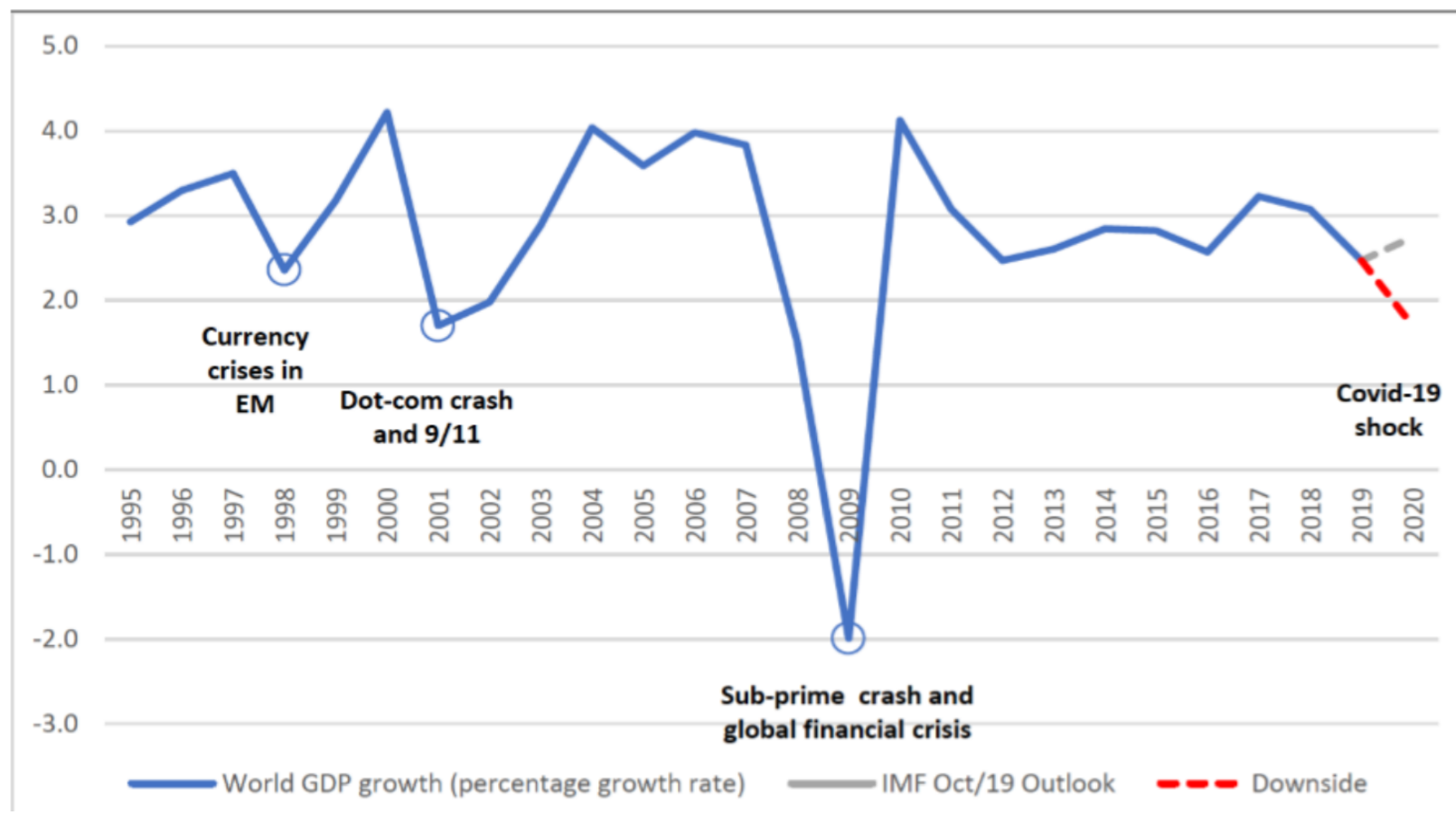

Figure 1. Global GDP growth, 1995-2020

Source: UNCTAD calculations based on IMF, WEO, October 2019 
In the final quarter of 2019, just three ventures enrolled a positive year-over-year development rate on the whole nation gatherings, specifically essential medical items, drinks, and food items. While these three ventures address fundamental essential buyer merchandise and are probably going to keep on performing above and beyond the coming months, other assembling enterprises are relied upon to endure an extreme blow because of the COVID episode and the subsequent financial ramifications. Thus, world GDP development can be relied upon to decrease in the coming months.

On the intriguing side, a blend of reduced compensation and fear of contamination will achieve lower private spending. But a part of these effects might be adjusted by extended government spending; the COVID-19 stagger's net interest sway is needed to be negative in the short run.

At last, extended peril shirking and a flight-to-liquidity notwithstanding weakness achieved by the COVID-19 paralyze, the pressing factor of the financial market will weigh energetically on the overall economy. Further fluctuations are ordinary in the new exchange market.

All around, projections suggest that inflows of external private cash to ODA-qualified countries in 2020 could plunge by USD 700 billion stood out from 2019 levels (Figure 02). With all wellsprings of external private records falling quickly, this presents an extraordinary squeezing element and financing void for making economies, outperforming the post-2008 Global Financial Crisis experience by $60 \%$ and moving toward $35 \%$ of the 2018 level of outside cash.

- Global Financial Crisis (2008) = COVID-19 (2020)

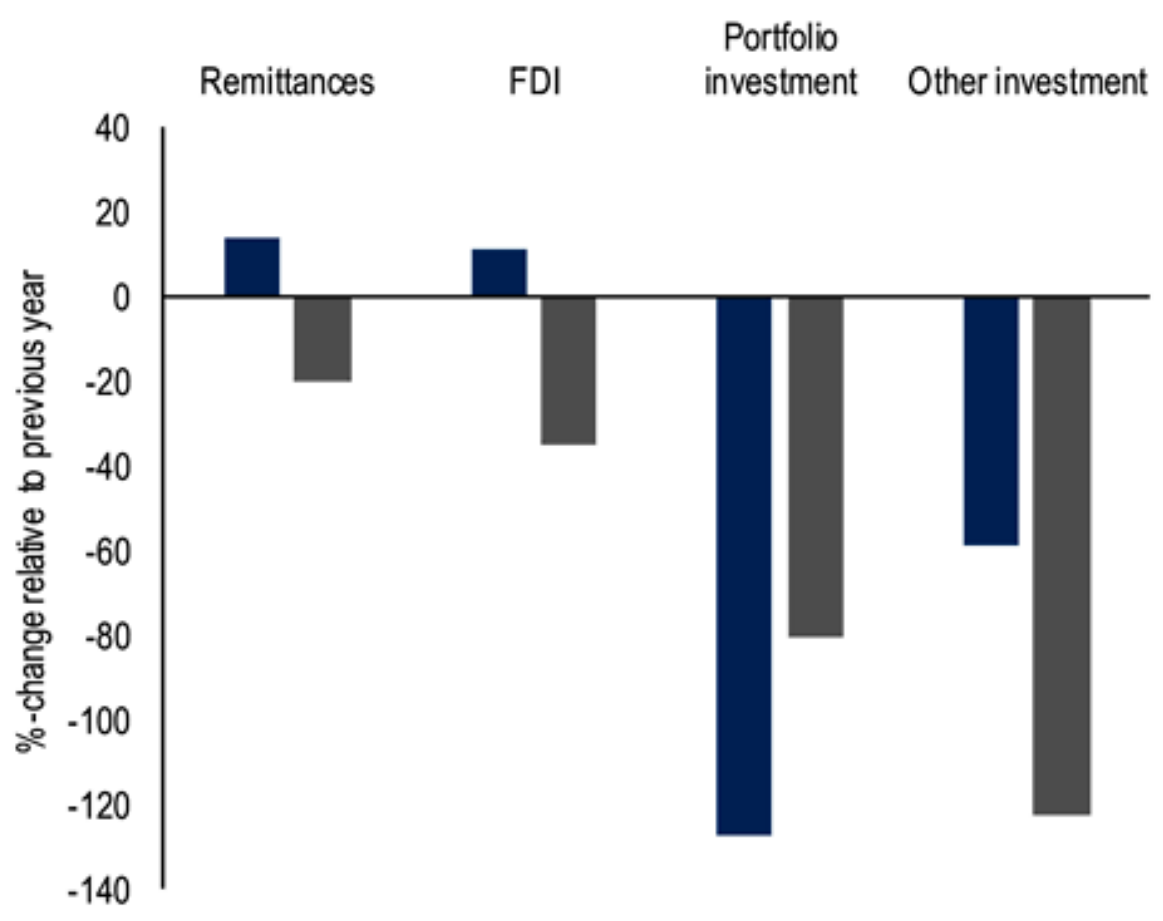

Figure 2 (A). The Overall COVID-19 Impact on External Private Finance in Developing Economies 


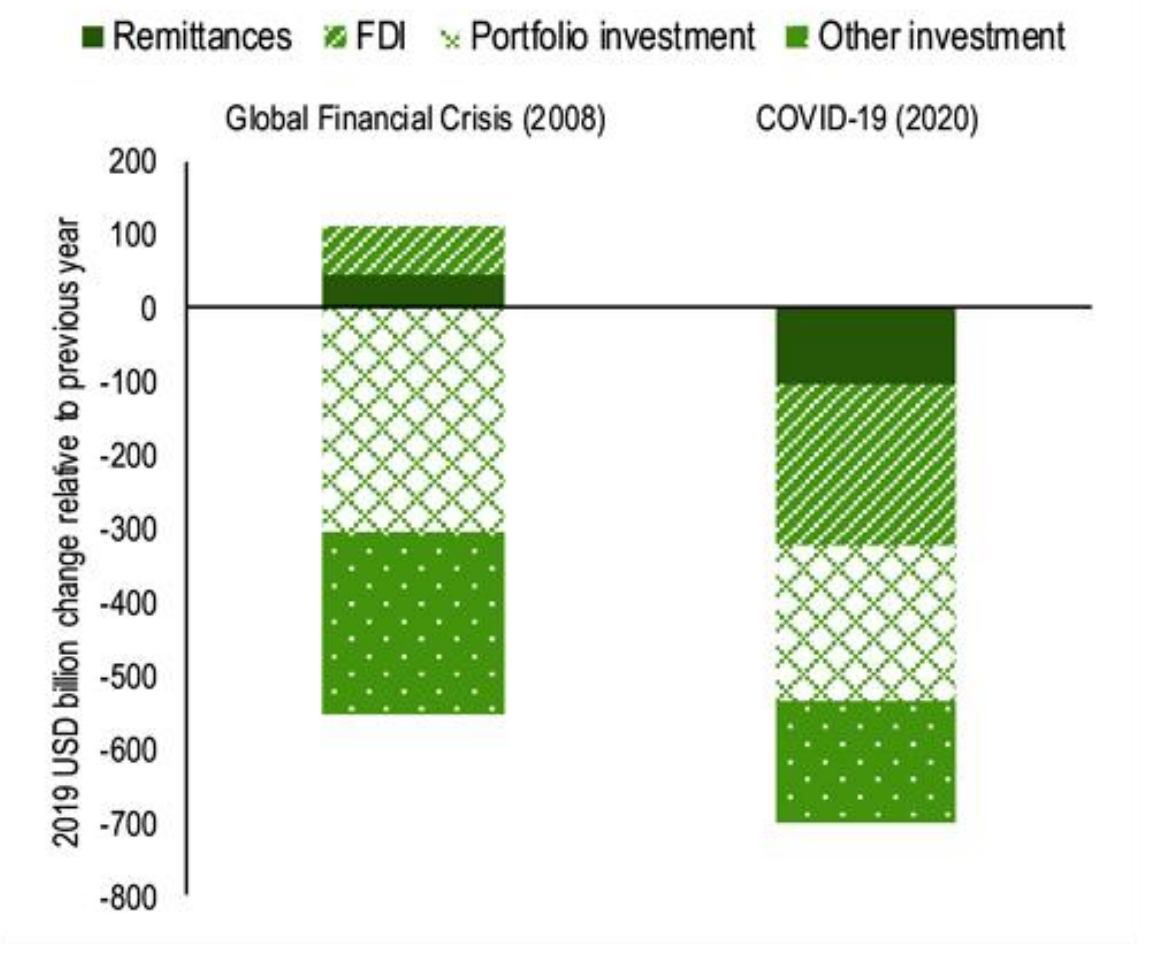

Figure 2 (B). The Overall COVID-19 Impact on External Private Finance in Developing Economies

Source: IMF Balance of Payments (IMF, 2020) and National Central Bank Data. World Bank World Development Indicators (2020).

In the steady times of the economy, primary changes that are put on the table pull in more consideration and are examined by the expense specialists. Be that as it may, uncommon periods where vacillations and consistency are negligible, for example, the COVID-19 period, are reasonable for creating strong reasoning for perspective changes. Also, it would be sensible currently to sell out substantial and elusive resources which have been intended to be moved between related organizations as market esteems would be lower if exists than it is in the steady time frames.

\section{CONCLUSION AND RECOMMENDATIONS}

Notwithstanding, as COVID-19 showed its effects, the principal issue is advanced from how the benefit is distributed among bunch organizations to the issue of danger acknowledgment and how the misfortune ought to be apportioned. Even though industrial facilities are shut and merchants can't sell because of the decreasing interest and store network disturbance, they continue bearing the inactive limit and working costs which are unavoidable. As it is known, the income that the organizations in the gathering ought to acquire is dictated by considering the capacities played out, the dangers attempted and the resources possessed. Notwithstanding, for the current situation, there is normally no income to be ascribed to any recipient.

As usual, rebuilding and changes in exchange estimating approaches will be inescapable for the progression of organizations and exercises since the COVID-19 emergency caused an 
unanticipated worldwide danger acknowledgment which couldn't be anticipated when the intrabunch authoritative connections were set up and the gathering activity model was planned.

Before settling on how many offers the organizations in the plan of action ought to get from benefit or misfortune, the matter of who controls the dangers ought to be looked into.

On the off chance that the plan of action of the worldwide undertakings contains generally safe level wholesalers or agreement makers which don't affect the dynamic system, the applicable organizations are relied upon to have a standard return dictated by one or the other expense in addition to or value-based net edge technique. Because of their low degree of danger, it can't be considered typical that those organizations get an offer from neither high benefit nor flighty misfortunes of the gathering.

A few issues, for example, breaks in the inventory network, the reducing interest, and the end of the exercises brought about by COVID-19 wellbeing emergency would lead worldwide endeavors to survey, change and somewhat or end a portion of their exchange estimating arrangements and plans of action.

The OECD is relied upon to distribute rules, as it did in the effect of the COVID-19 emergency on assessment deals, on how misfortune brought about by worldwide danger acknowledgment ought to be divided between the organizations inside a gathering, the impacts of conceivable restructurings and effect of financing instruments on a manageable distance nature of the intercompany exchanges.

Albeit the presence of conditions that require the requirement for strategy changes is frequently considered as negative, it can likewise be transformed into a chance by global endeavors.

\section{REFERENCES}

Antonakakis, N. C. (2013). Dynamic co-movements of stock market returns, implied volatility and policy uncertainty. Economics Letters, 120(1), 87-92.

Baret, S. C. (2020a). COVID-19 potential implications for banking and capital markets sector. Deloitte Insights, 8(2), 5-12. Retrieved December 1, 2020, from https://www2.deloitte.com/content/dam/insights/us/articles/6693_covid-19banking/DI_COVID-19-banking.pdf

Baret, S. C. (2020b). COVID-19 potential implications for the banking and capital markets sector. Maintaining Business And Operational Resilience, 11(8), 74-88.

Barua, S. (2020). Understanding Coronanomics: The economic implications of the coronavirus (COVID-19) pandemic. Asian Journal of Agricultural Extension Economics \& Sociology, 8(2), 24-38.

Bedford, J. (2020). COVID-19: towards controlling a pandemic. Lancet, 4(2), 38-49.

Buheji, M. (2020). Stopping Future COVID-19 like Pandemics from the Source-A SocioEconomic Perspective. American Journal of Economics, 115-125.

Chahrour, M. (2020). A bibliometric analysis of COVID-19 research activity: a call for increased output. Cureus, 6(2), 249-261. 
Chang, C. L. (2020). Alternative global health security indexes for risk analysis of COVID-19. International Journal of Environmental Research and Public Health, 17(9), 3161-3172.

Cheney, J. (2020). COVID-19 impact on bank liquidity risk management and response. Deloitte \& Touche LLP, 6(8), 72-88. Retrieved December 1, 2020, from https://www.deloitte.com/content/dam/Deloitte/us/Documents/regulatory/covidregulators-response.pdf

Chinazzi M, D. J. (2020). The effect of travel restrictions on the spread of the 2019 novel coronavirus (COVID-19) outbreak. Science.

Dua, A. J. (2020). COVID-19's effect on jobs at small businesses in the United States. Mckinsey \& Company, 8(3), 28-35. Retrieved December 1, 2020, from https://www.mckinsey.com/industries/social-sector/our-insights/covid-19s-effect-onjobs-at-small-businesses-in-the-united-states

Furman, J. (2020). Protecting people now, helping. . VoxEU eBook.

Gopinath, G. (2020). Limiting economic fallout. VoxEU eBook.

Hoque, A. S. (2020). The Effect of Coronavirus (COVID-19) in the Tourism Industry in China. Asian Journal of Multidisciplinary Studies, 3(1), 91-108.

Jim, D. (2020). How Is COVID - 19 Affecting Your Financial Statements. Forbes.

Johns Hopkins University. (2020). Coronavirus COVID-19 global cases by the Center for Systems Science and Engineering (CSSE). Johns Hopkins: Johns Hopkins University (JHU).

Khachfe, H. (2020). An epidemiological study on COVID-19: a rapidly spreading disease. Cureus, 3(4), 612-628.

Mann, C. L. (2020). 8 Real and financial lenses to assess the economic consequences of COVID-19. Economics in the Time of COVID-19, 81.

Mauro, R. B. (2020). Economics in the Time of COVID-19. VoxEU eBook.

McKibbin, W. J. (2020, March 2). The Global Macroeconomic Impacts of COVID-19: Seven Scenarios. CAMA Working Paper No. 19/2020, 3(1), 42-53. Retrieved from https://ssrn.com/abstract=3547729 or http://dx.doi.org/10.2139/ssrn.3547729

Ramelli, S. (2020). Feverish stock price reactions to covid-19.

Remuzzi, A. (2020). COVID-19 and Italy: what next? Lancet, 5(3), 78-88. 
Ruiz Estrada, M. A. (2020). The Application of the 2019-nCoV Global Economic Impact Simulator (the 2019-nCoV-GEI-Simulator) in China. SSRN Electronic Journal, 4(2), 98108.

Ryan, D. B. (2020). COVID-19 and the banking and capital markets industry. $P w C, 5(3), 48-57$. Retrieved December 1, 2020, from https://www.pwc.com/us/en/library/covid19/coronavirus-banking-and-capital-markets.html

S. Baret, A. C. (2020). COVID - 19 Potential Implications For The Banking And Capital Markets Sector. Maintaining Business And Operational Resilience. Deloitte Insights, 96108.

Spina, S. (2020). The response of Milan's emergency medical system to the COVID-19 outbreak in Italy. Lancet, 2(4), 49-50.

Vidovic, L. (2020). The Outlook For Corporate Credit Risk: COVID-19 Pandemic And Macroeconomic. S\&P Global, 6(7), 58-62.

WHO. (2020a, March 25). Coronavirus disease (COVID-2019) situation reports. Geneva: World Health Organization.

WHO. (2020b, March 20). Coronavirus disease (COVID-19) pandemic.

Xiang. (2020). Timely mental health care for the 2019 novel coronavirus outbreak is urgently needed. Lancet Psychiatry, 5(1), 28-29.

Ye, Z. (2020). COVID-19 and the Equity Market. A March 2020 Tale.

\section{Copyrights}

Copyright for this article is retained by the author(s), with first publication rights granted to the journal. This is an open-access article distributed under the terms and conditions of the Creative Commons Attribution license (http://creativecommons.org/licenses/by/4.0/) 